\title{
Uma revisão dos modelos para medição da qualidade em serviços
}

\author{
Paulo Augusto Cauchick Miguel \\ Núcleo de Gestão da Qualidade \& Metrologia \\ Faculdade de Engenharia Mecânica e de Produção, UNIMEP \\ Depto. Eng. de Produção - USP \\ E-mail:pamiguel@unimep.br; \\ Gilberto Eid Salomı \\ Núcleo de Gestão da Qualidade \& Metrologia \\ Faculdade de Engenharia Mecânica e de Produção, UNIMEP \\ E-mail: salomi_gilberto@yahoo.com
}

\begin{abstract}
Resumo
Este trabalho apresenta uma revisão da literatura sobre os principais modelos e conceitos propostos na literatura referentes à mensuração da qualidade de serviços externos. Tal revisão é de cunho analítico, temático, histórico e bibliográfico. Após a apresentação dos modelos, uma comparação entre eles é realizada destacando suas características principais, uma síntese das conclusões dos trabalhos, bem como a área de aplicação dos modelos (tipos de serviços]. Conclui-se que não existe um consenso na literatura quanto ao modelo para mensuração da qualidade em serviços mais apropriado. Além disso, existem questões ainda não respondidas, como a relação de casualidade entre qualidade dos serviços e satisfação de clientes, a influência do preço na satisfação do cliente e o uso dos modelos para avaliação da qualidade de serviços internos.
\end{abstract}

\section{Palavras-chave}

Qualidade em serviços, dimensões da qualidade, SERVPERF, SERVQUAL

\section{A literature review on models for measuring service quality}

\begin{abstract}
This paper presents a literature review on service quality evaluation. This review is an analytical, thematic, historical, and bibliographical work. It describes the main concepts and models on measuring external quality service proposed by the literature. After presenting the models, a comparison among them is carried out with regard to their main characteristics, conclusions of each one as well as the application areas of the models (types of services). The paper concludes that there is no literature consensus to be the most appropriate model for quality service measurement. Besides, there are still issues to be dealt with such as the relationship between service quality and satisfaction, the influence of price on customer satisfaction, and the use of quality service assessment models for measuring internal quality service.
\end{abstract}

\section{Key words}

Service quality, quality dimensions, SERVPERF, SERVQUAL 


\section{INTRODUĈ̣̃O}

É crescente a importância do setor de serviços na economia dos países desenvolvidos e em desenvolvimento. No Reino Unido, o setor de serviços compõe mais de $60 \%$ do PIB (SLACK, 2003). Ainda de acordo com o mesmo autor, o setor de serviços nos EUA, somado com o da União Européia, corresponde a mais de $50 \%$ do PIB dessas nações. No caso do Brasil, dados do IBGE (2002) indicam que o setor de serviços corresponde a cerca de $52,3 \%$ do PIB nacional.

Essa importância cada vez mais acentuada do setor de serviços caracteriza a necessidade de se empreender esforços em relação à mensuração da qualidade nos serviços prestados. Nesse sentido, ao longo do tempo, diversos pesquisadores têm dedicado esforços nesta área, buscando aprimorar sua conceituação e desenvolver técnicas de medição. Um dos precursores nessa direção foi Grönroos (1984), que desenvolveu um dos primeiros modelos para mensuração da qualidade em serviços. Mais tarde, Parasuraman et al. (1985) propuseram a medição de qualidade do serviço, baseado no modelo de satisfação de Oliver (1980), trabalho também desenvolvido por Brown; Swartz (1989). Em seguida, Parasuraman et al. (1988) complementaram seu modelo com um instrumento denominado SERVQUAL, baseado na avaliação de dimensões da qualidade para serviços (PARASURAMAN et al., 1990). A partir de então, vários autores têm se dedicado a esse campo de pesquisa, seja aperfeiçoando os modelos existentes (PARASURAMAN et al., 1991; 1994; TEAS, 1993), propondo outros modelos (BOLTON; DREW, 1991; CRONIN; TAYLOR, 1992), ou comparando-os (LEE et al., 2000).

Nesse contexto, este trabalho tem como objetivo principal apresentar os principais modelos de medição da qualidade dos serviços com base na literatura, comparando-os. São apresentados os instrumentos SERVQUAL, muito difundidos e referenciados em publicações, e SERVPERF, citados como os que apresentam os melhores índices de confiabilidade, além de outros modelos. Após a apresentação dos modelos, uma comparação entre eles é realizada, visando proporcionar uma revisão, segundo Noronha; Ferreira (2000), de cunho analítico, em relação ao propósito, temática e história, quanto a sua abrangência e função, respectivamente, e de cunho bibliográfico, segundo o tratamento e abordagem dados aos trabalhos analisados. Esses critérios metodológicos são esclarecidos a seguir.

\section{METODOLOGIA DA PESQUISA}

As revisões da literatura apresentam-se como atividade importante para identificar, conhecer e acompanhar o desenvolvimento da pesquisa em determinada área do conhecimento (NORONHA; FERREIRA, 2000), além de permitirem a cobertura de uma gama de fenômenos geralmente mais ampla do que aquela que poderia ser pesquisada diretamente (GIL, 1991). Além disso, as revisões permitem a identificação de perspectivas para pesquisas futuras, contribuindo com sugestões de idéias para o desenvolvimento de novos projetos de pesquisa (NORONHA; FERREIRA, 2000). Adicionalmente, desempenham importante papel na transferência de informação entre pesquisadores e seus pares, conforme atestam algumas pesquisas realizadas sobre sua utilização (BUTKOVICH, 1996; SAYERS et al., 1990). 
- Quanto ao tratamento e abordagem dados aos trabalhos analisados da revisão (bibliográficos ou críticos): o trabalho é bibliográfico, podendo ser considerado como uma bibliografia anotada, sem apontamento crítico aprofundado. Embora com ressalvas, o trabalho objetiva servir como subsídio para comparação das diferentes fontes, permitindo uma seleção daquelas de maior interesse relativo ao tema de medição da qualidade em serviços.

Uma vez estabelecida a linha metodológica deste trabalho, o tópico seguinte apresenta os modelos para mensuração da qualidade em serviços, baseado na literatura.

\section{MODELOS PARA AVALIAC̄̃̃O DA QUALIDADE EM SERVIC̣OS}

Neste tópico são apresentados os principais modelos propostos pela literatura, que têm sido amplamente discutidos e referenciados em diversos trabalhos, quanto ao seu desenvolvimento e adequação. Seis principais modelos, identificados na literatura, são apresentados, cuja descrição é feita na seqüência.

\section{Modelo de qualidade de serviço}

O modelo proposto por Grönroos (1984) considera a qualidade percebida de um serviço como função do serviço esperado e do serviço percebido, incluindo um terceiro fator, chamado de imagem da empresa. Ao adquirir um serviço, o consumidor faz uma avaliação de dimensões de cunho técnico e funcional. A dimensão que é resultado daquilo que é recebido durante a aquisição de um serviço é denominada de "qualidade técnica". A "qualidade funcional" é relativa ao nível de desempenho observado de forma subjetiva, sendo fortemente influenciada pela maneira como o serviço é prestado e intensamente dependente do contato com o prestador de serviço. O modelo representa então o conceito do que foi denominado como qualidade técnica, qualidade funcional, além de outros fatores menos influentes, destacados mais à frente.

Para aplicar o modelo, em 1981, utilizou-se um questionário destinado a executivos suecos representantes dos seguintes setores: bancário, securitário, hoteleiro, restaurantes, aéreo (companhias), manutenção e limpeza, locação de veículos e turismo (agências). As questões foram aplicadas na forma de escala Lickert de 5 pontos e são descritas na Tabela 1.

Tabela 1: Questionário Aplicado a Serviços Diversos (GRÖNROOS, 1984).

\begin{tabular}{|l|c|c|c|}
\hline \multicolumn{1}{|c|}{ QUESTÃo } & $\%$ (4) + \% (5) & No DE RESPOSTAS & SEM RESPOSTA \\
\hline $\begin{array}{l}\text { 1. Na maioria dos casos, o contato diário com os } \\
\text { clientes cinteração comprador - vendedor) é mais } \\
\text { importante que as atividades tradicionais de marketing, } \\
\text { tais como propaganda, comunicação de massa, etc. }\end{array}$ & 94,1 & 218 & 1 \\
\hline $\begin{array}{l}\text { 2. A imagem corporativa é formada mais pelo contato } \\
\text { do cliente com a companhia linteração comprador - } \\
\text { vendedor) que o resultado de atividades de marketing. }\end{array}$ & 88,8 & 216 & 3 \\
\hline $\begin{array}{l}\text { 3. As atividades tradicionais de marketing são de } \\
\text { importância marginal somente com relação à imagem } \\
\text { corporativa que os clientes têm da empresa no } \\
\text { momento presente. }\end{array}$ & 74,0 & 218 & 1 \\
\hline $\begin{array}{l}\text { 4. A comunicação pessoal tem um impacto mais } \\
\text { substancial nos consumidores potenciais que as } \\
\text { atividades tradicionais de marketing. }\end{array}$ & 83,5 & 216 & 3 \\
\hline $\begin{array}{l}\text { 5. A maneira de os atendentes conduzirem os contatos } \\
\text { com os clientes traz compensações por possíveis } \\
\text { problemas temporários de qualidade técnica. }\end{array}$ & 91,3 & 219 & 0 \\
\hline $\begin{array}{l}\text { 6. A maneira de os atendentes conduzirem os contatos } \\
\text { com os clientes, e sendo estes voltados para o cliente e } \\
\text { conscientes do serviço, traz compensações no caso de } \\
\text { um baixo nível de qualidade técnica. }\end{array}$ & 37,9 & 217 & 2 \\
\hline
\end{tabular}


Analisando-se o percentual das respostas do questionário, uma grande proporção de respondentes "concorda" e "concorda fortemente" com as cinco primeiras afirmativas e discorda com a sexta (a coluna na Tabela 1 mostra a somatória dessas respostas). Foi possível então afirmar que a interação entre vendedor e comprador (questões 1 a 4) é de grande importância para o setor de serviços e mais importante até que as atividades tradicionais de marketing.

A qualidade funcional tem grande influência na qualidade perceptível do serviço, sendo capaz de compensar possíveis falhas ocorridas no decorrer da sua aquisição (vide questão 5 na Tabela 1). No caso, as promessas feitas sobre o serviço, por meio das atividades de marketing, devem ser realísticas, a fim de não aumentar o nível de expectativa do cliente e gerar uma insatisfação futura.

Grönroos (1984) dá maior ênfase à dimensão funcional, afirmando que o consumidor não está interessado somente no que recebe, à semelhança de um processo de produção, mas no processo propriamente dito. A qualidade percebida é o resultante da diferença entre a expectativa do cliente e o seu julgamento sobre o desempenho do serviço, em relação a uma série de características, algumas técnicas e outras funcionais.

Considera, ainda, a imagem da empresa como uma terceira variável no modelo de qualidade do serviço, que abrange o local e os seus recursos disponíveis durante o consumo. Pode ser considerada como uma dimensão da qualidade, por meio da qual os clientes formam seu conceito da empresa e têm as suas expectativas influenciadas por este conceito. A imagem da empresa seria construída, principalmente, pelas qualidades técnicas e funcionais, além de outros fatores menos influentes, tais como reputação, informações de terceiros, propaganda, preço e relações públicas.

Apesar do trabalho de Grönroos (1984) simplesmente apresentar o percentual para cada uma das questões aplicadas, ele norteia inúmeros trabalhos subseqüentes, ressaltando pontos importantes que devem ser considerados para que uma empresa de serviços seja competitiva: definir como a qualidade é percebida pelos consumidores e determinar de qual forma a qualidade dos serviços é influenciada.

\section{Modelo Gap e instrumento SERVQUAL}

Parasuraman et al. (1985) propuseram a medição de qualidade do serviço, baseados no modelo de satisfação de Oliver (1980), afirmando que a satisfação do cliente é uma função da diferença entre expectativa e desempenho. Assim, a avaliação $\mathrm{Q}_{\mathrm{i}}$ de um serviço pelos clientes em relação a uma dimensão i é feita pela diferença entre a sua expectativa $\mathrm{E}_{\mathrm{i}} \mathrm{e}$ o seu julgamento sobre o serviço $D_{i}$, para dimensões $i$ da qualidade em serviço (equação 1 ).

$\mathrm{Q}_{\mathrm{i}}=\mathrm{D}_{\mathrm{i}}-\mathrm{E}_{\mathrm{i}}$

O Gap, ou diferença entre a expectativa e a percepção de desempenho, além de ser uma medida da satisfação do cliente, também seria uma medida da qualidade do serviço em relação a uma dimensão específica. Essas dimensões da qualidade seriam características genéricas do serviço, subdivididas em itens, que somadas resultariam no serviço como um todo, sob o ponto de vista do cliente que irá julgá-lo.

\section{A ausência de medidas objetivas para avaliar de complexidade em relação a sua avaliação.}

A fim de testar o modelo, uma pesquisa exploratória envolveu entrevistas com executivos pertencentes a empresas americanas reconhecidas de quatro diferentes tipos de serviços: banco varejista, cartão de crédito, corretagem de ações, reparo e manutenção, envolvendo 12 grupos de foco (focus groups), com o objetivo de aumentar o conhecimento sobre os seguintes pontos:

- Identificar o que os gestores de serviço perceberiam como atributos-chave de qualidade;

- Definir os problemas e tarefas envolvidos no gerenciamento da qualidade dos serviços;

- Identificar quais seriam os atributos-chave da qualidade dos serviços, sob o ponto de vista dos clientes;

- Determinar quais as discrepâncias (lacunas) entre a percepção dos clientes e dos responsáveis pelo marketing das empresas;

- Estabelecer quais os pontos comuns entre a percepção dos clientes e gestores que podem ser combinados em um modelo geral, que também represente a qualidade do serviço, sob o ponto de vista dos clientes.

Dessa forma, do conjunto de entrevistas, observaramse pontos comuns a todos os quatro tipos de serviços estudados, os quais podem ser representados pelo modelo ilustrado na Figura 1.

O Gap 1 compreende a discrepância entre a expectativa do cliente e a percepção gerencial. Um exemplo gera- 
do nos grupos de foco e entrevistas seria o de uma empresa improvável de ser apontada como um exemplo de alto nível de qualidade, mas que fosse considerada pelos seus executivos como tendo a qualidade dos seus serviços como ponto forte.

O Gap 2 consiste na discrepância entre a percepção gerencial sobre as expectativas dos clientes com as especificações da qualidade dos serviços. As entrevistas mostraram, de forma consistente, que uma das causas do baixo nível de qualidade para os executivos foi o fornecimento de um serviço de baixa qualidade, mesmo em empresas que tinham procedimentos detalhados sobre o que fazer e como tratar seus clientes.

Como as empresas de serviço são altamente dependentes do contato interpessoal para o fornecimento de seus serviços, o Gap 3 exprime a discrepância entre os padrões e especificações da empresa e o que realmente é fornecido ao cliente.

O Gap 4 considera a discrepância entre a promessa realizada pelos meios de comunicação e o que realmente é fornecido. Por exemplo, a propaganda pode anunciar características de um serviço que podem não ser cumpridas, e assim gerar uma distorção na expectativa do cliente, ocasionando uma diminuição na percepção do nível de qualidade do serviço.

Concluiu-se que julgamentos de serviços considerados como de alta ou de baixa qualidade dependiam de como os clientes percebiam o real desempenho do serviço, no contexto de suas próprias expectativas. Assim, propôs-se o Gap 5 ou a discrepância entre a expectativa do cliente e a sua percepção do serviço, podendo ser expresso como função dos outros Gaps. Nesse sentido, a percepção de qualidade dos serviços pelo cliente depende da direção e magnitude dos outros Gaps, associados com projeto, marketing e entrega dos serviços de uma empresa. Outra conclusão importante foi que os consumidores utilizam os mesmos critérios para chegar a um julgamento sobre a qualidade do serviço prestado, independentemente do tipo de serviço considerado. Estes critérios puderam ser generalizados em 10 categorias

Figura 1: Modelo Gap de Qualidade dos Serviços (PARASURAMAN et al. 1985).

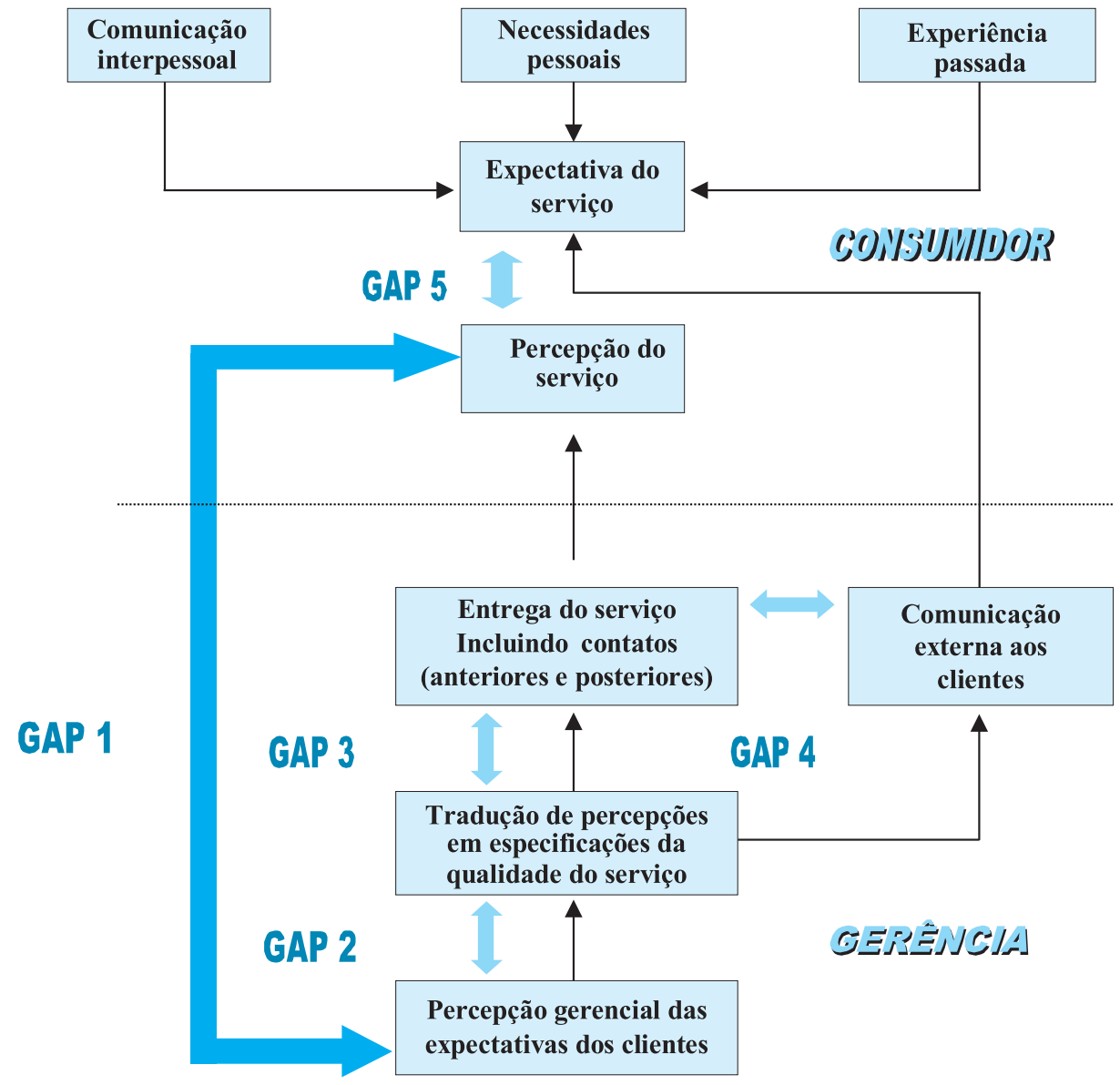


descritas na Tabela 2, inicialmente chamados de determinantes da qualidade e posteriormente denominados de dimensões da qualidade.

As dimensões da qualidade representam os pontos críticos na prestação de um serviço, que podem causar a discrepância entre expectativa e desempenho, que devem ser minimizadas a fim de se alcançar um padrão adequado de qualidade.

O modelo Gap explicita as influências das várias discrepâncias ocorridas na qualidade dos serviços, divididas em dois segmentos distintos: o contexto gerencial e o contexto do cliente. No contexto gerencial direciona-se a análise de cada Gap para uma melhoria no fornecimento dos serviços. No contexto do cliente, mostra-se como este faz a sua avaliação de qualidade através dos eventos de satisfação para cada um dos itens que compõem as dimensões da qualidade. No modelo idealizado, o cliente tem uma ou mais expectativas para cada uma das dimensões da qualidade, em relação ao serviço a ser adquirido.

No decorrer do processo de compra e mesmo após a compra, o cliente compara a sua expectativa com o seu julgamento do desempenho, para cada item da dimensão

Tabela 2: Determinantes da qualidade (PARASURAMAN et al.,1985).

\begin{tabular}{|c|c|}
\hline DETERMINANTE & CONGEITO \\
\hline Confiabilidade & $\begin{array}{l}\text { Abrange consistência de desempenho e confiabilidade. Também significa que a empresa honra } \\
\text { seus compromissos. Especificamente envolve: precisão nas contas, manutenção dos } \\
\text { registros de forma correta e realização do serviço no tempo designado. }\end{array}$ \\
\hline Presteza & $\begin{array}{l}\text { Refere-se ao desejo e presteza que os empregados têm em prover os serviços. Envolve } \\
\text { rapidez nos serviços, por exemplo: postar um recibo ou contatar um cliente rapidamente, ou } \\
\text { realizar rapidamente um serviço. }\end{array}$ \\
\hline Competência & $\begin{array}{l}\text { Significa possuir as habilidades necessárias e conhecimento para realizar o serviço, } \\
\text { envolvendo: conhecimento e habilidade do pessoal de atendimento, conhecimento e habilidade } \\
\text { do pessoal de apoio operacional, capacidade de pesquisa da organização. }\end{array}$ \\
\hline Acessibilidade & $\begin{array}{l}\text { Refere-se a proximidade e a facilidade de contato, significando que: o serviço pode ser } \\
\text { acessível por telefone, o tempo de espera para receber o serviço não é muito extenso, tem } \\
\text { um horário de funcionamento e localização conveniente. }\end{array}$ \\
\hline Cortesia & $\begin{array}{l}\text { Abrange educação, respeito, consideração e amabilidade do pessoal de atendimento. } \\
\text { Compreende também consideração com a propriedade do cliente (por exemplo: não usar } \\
\text { sapatos sujos no carpete). }\end{array}$ \\
\hline Comunicação & $\begin{array}{l}\text { Significa manter os clientes informados em linguagem que sejam capazes de compreender. } \\
\text { Pode significar que a companhia deve ajustar sua linguagem para diferentes consumidores, } \\
\text { aumentando o nível e sofisticação para os mais bem educados e conversando de maneira } \\
\text { simples e direta com os mais simples. Também compreende: proporcionar explicação do } \\
\text { serviço, preços, descontos e garantir ao consumidor que um eventual problema será resolvido. }\end{array}$ \\
\hline Credibilidade & $\begin{array}{l}\text { Considera a honestidade e implica em que a empresa esteja comprometida em atender aos } \\
\text { interesses e objetivos dos clientes, abrange: nome e reputação da empresa, características } \\
\text { pessoais dos atendentes e nível de interação com os clientes durante a venda. }\end{array}$ \\
\hline Segurança & $\begin{array}{l}\text { Ausência de perigo, risco ou dúvidas, abrangendo: segurança física, financeira e } \\
\text { confidencialidade. }\end{array}$ \\
\hline $\begin{array}{l}\text { Compreensão e } \\
\text { Conhecimento do } \\
\text { cliente }\end{array}$ & $\begin{array}{l}\text { Significa esforçar-se para compreender as necessidades dos clientes, envolvendo: } \\
\text { aprendizado sobre os requisitos específicos do cliente, proporcionar atenção individualizada, } \\
\text { reconhecer clientes constantes e preferenciais. }\end{array}$ \\
\hline Aspectos Tangíveis & $\begin{array}{l}\text { Significa a inclusão e demonstração de evidências físicas ao serviço, tais como instalações, } \\
\text { aparência do pessoal, ferramentas e equipamentos utilizados no serviço, representação } \\
\text { física do serviço, tais como um cartão de crédito plástico, ou uma prestação de contas, } \\
\text { além de outros clientes presentes nas instalações. }\end{array}$ \\
\hline
\end{tabular}


da qualidade, formando um conceito único que será definido como a qualidade perceptível dos serviços. A formação da expectativa tem como base três pontos principais: a comunicação interpessoal, necessidades pessoais e experiência passada, em uma contínua renovação, conforme é ilustrado na Figura 2.

Parasuraman et al. (1985) também afirmam que os clientes avaliam a qualidade dos serviços de forma global, de modo similar a uma atitude. Salientam que a atitude é conceituada por Oliver (1981) como a duradoura orientação afetiva de um cliente em relação a um estabelecimento comercial, produto ou processo, enquanto que satisfação é a reação emocional a uma experiência, resultante da não-confirmação de uma expectativa prévia, a qual atua no nível da atitude de consumo. Atitude pode ser, conseqüentemente, medida em termos mais gerais, a produtos e estabelecimentos, sendo por isso menos situacional.

Apesar da forte relação entre qualidade e satisfação, faz-se necessário ressaltar as devidas distinções no domínio dos trabalhos referenciados. A qualidade de serviços observável ou perceptível é conceituada como um julgamento global, enquanto a satisfação é relacionada a um fato ou transação específica. Estas distinções consideradas por Parasuraman et al. (1985) têm como base a pesquisa exploratória com os grupos de foco, onde houve várias ocorrências de satisfação de clientes com um determinado serviço sem que, no entanto, sentissem ou julgassem que este fosse de alta qualidade.

Resumindo, pode-se afirmar que, ao longo da aquisição de um serviço, as diversas ocorrências de satisfação resultam em um julgamento da qualidade deste. Parasuraman et al. (1988), tomando como base as 10 dimensões da qualidade (Tabela 2), desenvolveram um questionário chamado de escala (ou instrumento) SERVQUAL (representado na Tabela 3), utilizando as diversas ocorrências de satisfação por meio do modelo Gap. Foram identificados inicialmente 97 itens, distribuídos pelos 10 determinantes da qualidade, capazes de caracterizar as percepções de qualidade. As empresas pesquisadas representavam os seguintes serviços: reparo e manutenção de produtos, banco varejista, chamada telefônica de longa-distância, corretagem de ações e operação de cartão de crédito, considerados como representativos do setor de serviços (LOVELOCK apud PARASURAMAN et al., 1988).

A escala ou conjunto de 97 itens, relativos à expectativa, e 97 itens relativos à percepção de qualidade foi refinada, em três estágios, coletando-se dados de 200 respondentes adultos igualmente divididos entre homens e mulheres. Cada item inicial foi refeito no formato de duas declarações. Uma fazia referência à expectativa do serviço e a outra à percepção de qualidade da empresa em questão. Aproximadamente metade dos itens foi escrita no formato afirmativo e outra metade, negativamente. Para se qualificar para a pesquisa os respondentes deveriam ter usado os serviços durante os três meses anteriores.

Determinou-se o coeficiente de correlação alfa de Cronbach (ver HAYES, 1997) separadamente por dimensão, encontrando-se valores que variavam de 0,55 a 0,78 (o valor ideal corresponde a 1 ). A análise destes valores sugeria a eliminação de alguns itens para melho-

Figura 2: Determinantes da Qualidade dos Serviços (PARASURAMAN et al., 1985).

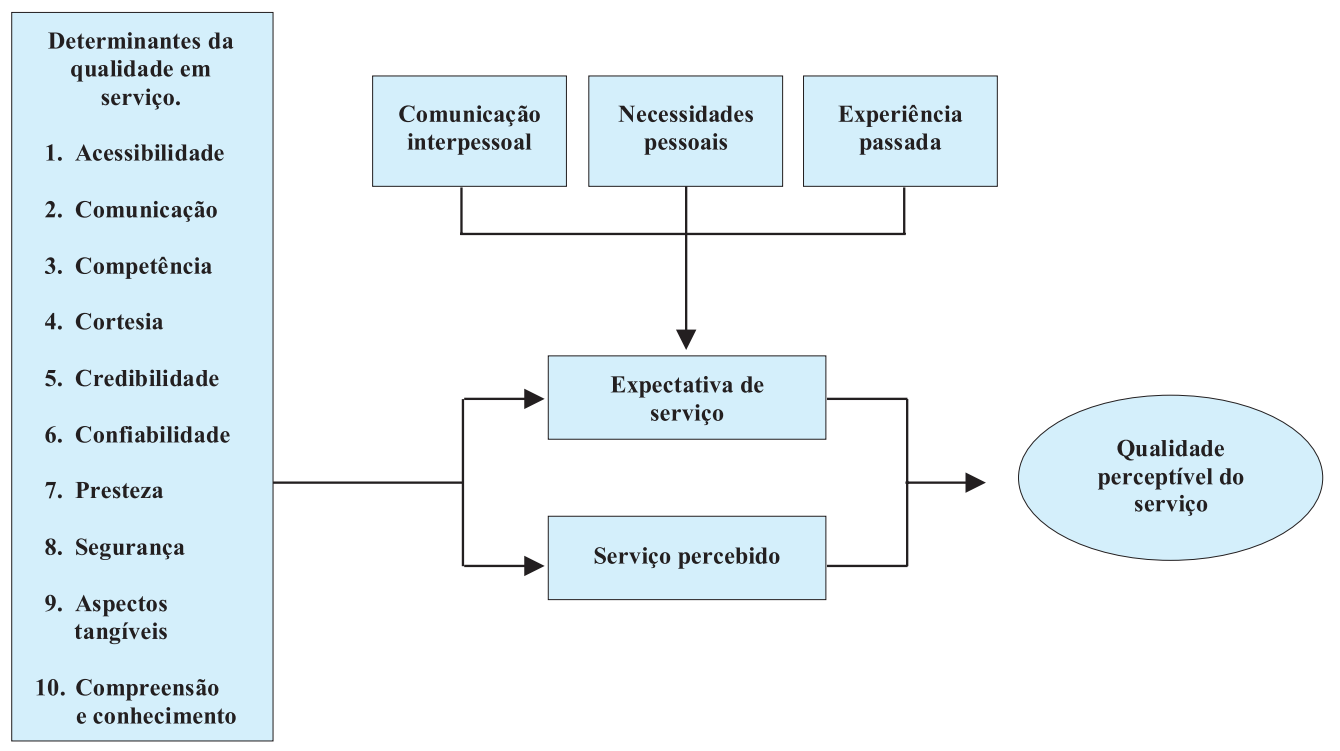


rar a confiabilidade do questionário. Em um primeiro refinamento da escala, chegou-se a 54 itens distribuídos entre as 10 dimensões, com o coeficiente alfa atingindo valores de 0,72 a 0,83 . Prosseguindo com o refinamento da escala, foi alcançado um resultado de cinco dimensões da qualidade, caracterizadas por 22 itens, sendo as seguintes:

- Confiabilidade: capacidade de realizar um serviço prometido de forma confiável e precisa.

- Presteza: ajudar o cliente e prover pronto atendimento.

- Segurança: habilidade em transmitir confiança e segurança, com cortesia e conhecimento.

- Empatia: cuidados e atenção individualizados aos clientes.

- Aspectos Tangíveis: instalações, equipamentos, pessoal envolvido e material de comunicação.

Os 22 itens mostrados na Tabela 3, distribuídos pelas cinco dimensões anteriores, não são descritos genericamente, mas por meio de afirmações e negações, representando características específicas para cada dimensão, utilizando uma escala Lickert de 7 pontos, variando de (1) "discordo fortemente" a (7) "concordo fortemente". Estas cinco dimensões da qualidade obtidas pela pesquisa, após nova análise e eliminação de itens, apresentaram coeficiente alfa, por dimensão, variando de 0,72 a 0,86 , sendo o menor para aspectos tangíveis e o maior para empatia, com um coeficiente alfa total da escala de 0,92. As 10 dimensões iniciais, posteriormente reduzidas a cinco, são mostradas na Figura 3, com os números dos respectivos itens do formato final proposto.

Posteriormente, Parasuraman et al. (1991) refinaram o instrumento SERVQUAL, baseados em levantamento empírico em cinco empresas de serviço. As expressões originais "deveriam", que poderiam contribuir negativamente para um aumento de expectativa do entrevistado, foram substituídas por outras que retratavam a expectativa do que os clientes considerariam como serviços excelentes. Além desta mudança, todas as expressões negativas foram substituídas por expressões afirmativas e dois itens foram substituídos, com a finalidade de refletir mais fielmente as dimensões representadas. Com essas alterações, a análise de regressão apresentou resultados mais consistentes, sendo o valor do coeficiente de Pearson $\left(\mathrm{R}^{2}\right)$ maior que 0,57 para todas as empresas investigadas.

Desde a proposta inicial da escala SERVQUAL, uma intensa controvérsia iniciou-se sobre a sua adequação e possibilidade de generalização para as diversas áreas do setor de serviços externos. Por exemplo, Carman (1990) afirmou que esta escala não poderia ser genérica e aplicada a todos os tipos de serviço, devendo ser adaptada a serviços específicos. Babakus; Boller (1992) também concluíram que as dimensões consideradas dependeriam do tipo de serviço avaliado. Além disto, confirmaram resultados mais consistentes para modelos baseados somente na percepção de desempenho em contraposição aos modelos baseados na diferença entre expectativa e desempenho. Estes argumentos foram minuciosamente contestados em trabalhos subseqüentes, descritos mais à frente.

\section{Modelo percepção-expectativa}

Brown e Swartz (1989) propuseram também um modelo de qualidade em serviços também baseado no modelo de satisfação de Oliver (1980). Este modelo considerava a qualidade como a diferença entre expectativa e percepção de desempenho (equação 2). Conceitualmente é semelhante ao modelo SERVQUAL, que considera a qualidade como a diferença entre percepção de desempenho e expectativa (equação 1). Analiticamente, a avaliação do serviço pelo cliente poderia ser expressa como:

$$
\begin{aligned}
& \mathrm{Q}_{\mathrm{i}}=\mathrm{E}_{\mathrm{i}}-\mathrm{D}_{\mathrm{i}} \\
& \mathrm{D}_{\mathrm{i}}=\mathrm{f}\left(\mathrm{D}_{\mathrm{j}}\right), \quad \mathrm{t}_{0}<\mathrm{t}_{1}
\end{aligned}
$$

Onde:

$\mathrm{D}_{\mathrm{i}}=$ Medida de percepção de desempenho para característica i do serviço, em um momento $t_{1}$.

$\mathrm{E}_{\mathrm{i}}=$ Medida da expectativa de desempenho para característica i do serviço.

$\mathrm{Q}_{\mathrm{i}}=$ Avaliação da qualidade do serviço em relação à característica i.

$\mathrm{D}_{\mathrm{j}}=$ Medida de percepção de desempenho para característica i do serviço em situações anteriores à da avaliação $D_{i}$.

Os Gaps ou discrepâncias propostas foram:

- Gap 1 = Percepção de desempenho do profissional julgado pelo cliente.

- Gap 2 = Percepção do profissional em relação à expectativa do cliente. 
Tabela 3: O Instrumento SERVQUAL (PARASURAMAN et al., 1988).

\begin{tabular}{|c|c|c|}
\hline ITEM & EXPECTATIVA (E) & DESEMPENHO (D) \\
\hline 1 & Ela deveria ter equipamentos modernos. & XYZ tem equipamentos modernos. \\
\hline 2 & $\begin{array}{l}\text { As suas instalações físicas deveriam ser visualmente } \\
\text { atrativas. }\end{array}$ & $\begin{array}{l}\text { As instalações físicas de XYZ são } \\
\text { visualmente atrativas. }\end{array}$ \\
\hline 3 & $\begin{array}{l}\text { Os seus empregados deveriam estar bem-vestidos e } \\
\text { asseados. }\end{array}$ & $\begin{array}{l}\text { Os empregados de XYZ são bem-vestidos e } \\
\text { asseados. }\end{array}$ \\
\hline 4 & $\begin{array}{l}\text { A aparência das instalações da empresa deveria estar } \\
\text { conservada de acordo com o serviço oferecido. }\end{array}$ & $\begin{array}{l}\text { A aparência das instalações físicas de XYZ } \\
\text { é conservada de acordo com o serviço oferecido. }\end{array}$ \\
\hline 5 & $\begin{array}{l}\text { Quando estas empresas prometem fazer algo em certo } \\
\text { tempo deveriam fazê-lo. }\end{array}$ & $\begin{array}{l}\text { Quando XYZ promete fazer algo em certo } \\
\text { tempo, realmente o faz. }\end{array}$ \\
\hline 6 & $\begin{array}{l}\text { Quando os clientes têm algum problema com esta } \\
\text { empresa ela deveria ser solidária e deixá-los } \\
\text { seguros. }\end{array}$ & $\begin{array}{l}\text { Quando você tem algum problema com a } \\
\text { empresa } X Y Z \text {, ela é solidária e o deixa } \\
\text { seguro. }\end{array}$ \\
\hline 7 & Esta empresa deveria ser de confiança. & XYZ é de confiança. \\
\hline 8 & Ela deveria fornecer o serviço no tempo prometido. & XYZ fornece o serviço no tempo prometido. \\
\hline 9 & $\begin{array}{l}\text { Ela deveria manter seus registros de forma } \\
\text { correta. }\end{array}$ & $\begin{array}{l}\text { XYZ mantém seus registros de forma } \\
\text { correta. }\end{array}$ \\
\hline 10 & $\begin{array}{l}\text { Não seria de se esperar que ela informasse os clientes } \\
\text { exatamente quando os serviços fossem executados. }\end{array}$ & $\begin{array}{l}\text { XYZ não informa exatamente quando os } \\
\text { serviços serão executados. }\end{array}$ \\
\hline 11 & $\begin{array}{l}\text { Não é razoável esperar por uma disponibilidade imediata } \\
\text { dos empregados da empresa. }\end{array}$ & $\begin{array}{l}\text { Você recebe serviço imediato dos } \\
\text { empregados da } X Y Z \text {. }\end{array}$ \\
\hline 12 & $\begin{array}{l}\text { Os empregados das empresas não têm que estar } \\
\text { sempre disponíveis em ajudar os clientes. }\end{array}$ & $\begin{array}{l}\text { Os empregados da XYZ não estão sempre } \\
\text { dispostos a ajudar os clientes. }\end{array}$ \\
\hline 13 & $\begin{array}{l}\text { É normal que eles estejam muito ocupados em responder } \\
\text { prontamente aos pedidos. }\end{array}$ & $\begin{array}{l}\text { Empregados da XYZ estão sempre ocupados } \\
\text { em responder aos pedidos dos clientes. }\end{array}$ \\
\hline 14 & $\begin{array}{l}\text { Clientes deveriam ser capazes de acreditar nos } \\
\text { empregados desta empresa. }\end{array}$ & $\begin{array}{l}\text { Você pode acreditar nos empregados da } \\
\text { XYZ. }\end{array}$ \\
\hline 15 & $\begin{array}{l}\text { Clientes deveriam ser capazes de se sentir seguros } \\
\text { na negociação com os empregados da empresa. }\end{array}$ & $\begin{array}{l}\text { Você se sente seguro em negociar com os } \\
\text { empregados da } X Y Z \text {. }\end{array}$ \\
\hline 16 & Seus empregados deveriam ser educados. & Empregados da XYZ são educados. \\
\hline 17 & $\begin{array}{l}\text { Seus empregados deveriam obter suporte adequado da } \\
\text { empresa para cumprir suas tarefas corretamente. }\end{array}$ & $\begin{array}{l}\text { Os empregados da XYZ não obtêm suporte } \\
\text { adequado da empresa para cumprir suas } \\
\text { tarefas corretamente. }\end{array}$ \\
\hline 18 & $\begin{array}{l}\text { Não seria de esperar que a empresa desse atenção } \\
\text { individual aos clientes. }\end{array}$ & XYZ não dá atenção individual a você. \\
\hline 19 & $\begin{array}{l}\text { Não se pode esperar que os empregados dêem atenção } \\
\text { personalizada aos clientes. }\end{array}$ & $\begin{array}{l}\text { Os empregados da XYZ não dão atenção } \\
\text { pessoal. }\end{array}$ \\
\hline 20 & $\begin{array}{l}\text { É absurdo esperar que os empregados saibam quais são } \\
\text { as necessidades dos clientes. }\end{array}$ & $\begin{array}{l}\text { Os empregados da XYZ não sabem das } \\
\text { suas necessidades. }\end{array}$ \\
\hline 21 & $\begin{array}{l}\text { É absurdo esperar que esta empresa tenha os melhores } \\
\text { interesses de seus clientes como objetivo. }\end{array}$ & $\begin{array}{l}\text { XYZ não tem os seus melhores interesses } \\
\text { como objetivo. }\end{array}$ \\
\hline 22 & $\begin{array}{l}\text { Não deveria se esperar que o horário de funcionamento } \\
\text { fosse conveniente para todos os clientes. }\end{array}$ & $\begin{array}{l}\text { XYZ não tem os horários de funcionamento } \\
\text { convenientes a todos os clientes. }\end{array}$ \\
\hline
\end{tabular}

(1)

(2)

(3)

(4)

[5]

(6)

(7)

Discordo

Fortemente

Concordo

Fortemente 
- Gap 3 = Percepção do profissional em relação ao desempenho julgado pelo cliente.

O modelo ilustrado na Figura 4, apesar de não diferir substancialmente se comparado ao trabalho de Parasuraman et al. (1985), traz uma simplificação na análise do serviço no âmbito gerencial.

$\mathrm{O}$ modelo foi aplicado à área médica, envolvendo 13 profissionais com consultórios, nas especialidades de medicina interna e familiar. Foram enviados questionários usando a escala Lickert de 5 pontos (1 - "discordo fortemente" a 5 - "concordo fortemente"), em 10 dimensões da qualidade (Tabela 2). Foram obtidas 1.128 respostas e com a análise estatística dos dados não foi possível refutar duas das três hipóteses propostas.

A primeira hipótese não rejeitada foi que quanto maior a discrepância entre expectativa do cliente e o desempenho perceptível do serviço, menor o nível de satisfação (Gap 1). A segunda hipótese, também não rejeitada, foi que o nível positivo de avaliação do serviço profissional

Figura 3: Evolução nas Dimensões da Qualidade (PARASURAMAN et al., 1988).

\begin{tabular}{|c|c|c|c|c|c|}
\hline \multicolumn{6}{|c|}{ DIMENSÕES SERVQUAL } \\
\hline $\begin{array}{l}\text { Dez dimensões } \\
\text { originais }\end{array}$ & Aspectos Tangíveis & Confiabilidade & Presteza & Segurança & Empatia \\
\hline Aspectos Tangíveis & questões 1 a 4 & & & & \\
\hline Confiabilidade & & questões 5 a 9 & & & \\
\hline Presteza & & & questões 10 a 13 & & \\
\hline Competência & & & & questões 14 a 17 & \\
\hline Cortesia & & & & & \\
\hline Credibilidade & & & & & \\
\hline Segurança & & & & & \\
\hline Acessibilidade & & & & & questões 18 a 22 \\
\hline Comunicação & & & & & \\
\hline $\begin{array}{l}\text { Compreensão/ } \\
\text { conhecimento do } \\
\text { cliente }\end{array}$ & & & & & \\
\hline
\end{tabular}

Figura 4: Modelo para Qualidade de Serviços (BROWN e SWARTZ, 1989).

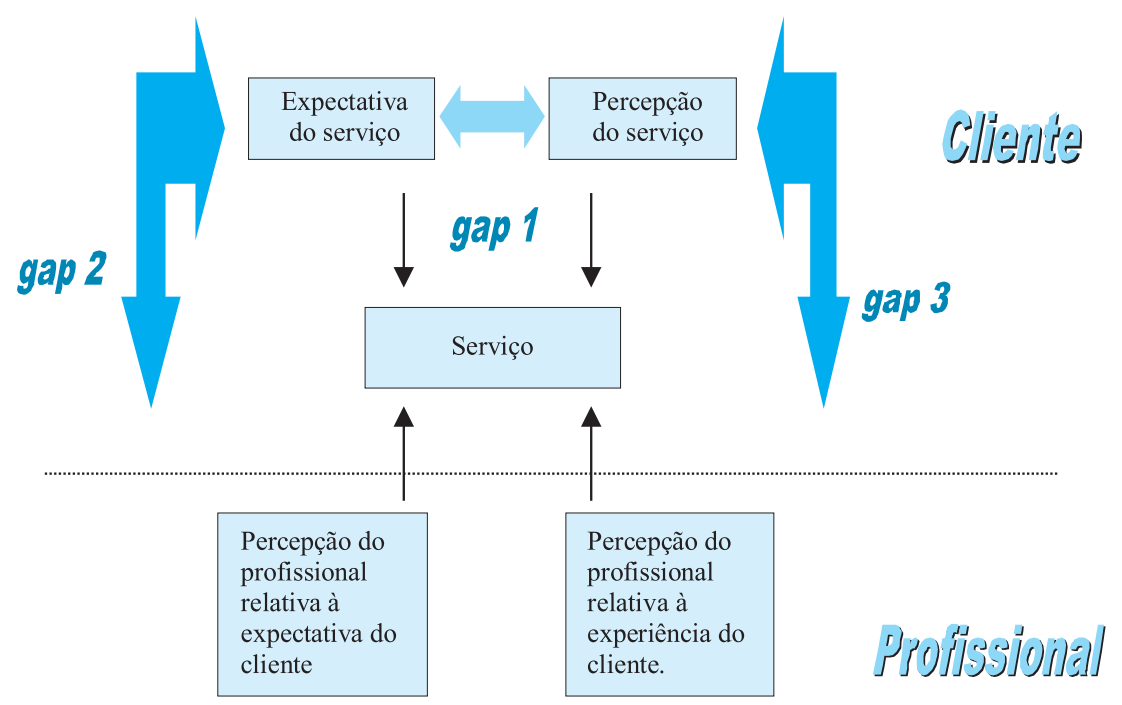


pelo cliente é diretamente proporcional ao Gap 3, ou seja, maior será o nível de satisfação do cliente quanto melhor for o nível de percepção do serviço pelo próprio profissional que presta o serviço. A terceira hipótese testada e rejeitada foi que seria maior o nível de satisfação quanto menor a discrepância entre expectativa do cliente e a percepção desta expectativa pelo profissional (Gap 2). No entanto, os próprios pesquisadores, em uma análise crítica, suspeitaram da confiabilidade das afirmativas relativas às expectativas, podendo não ter retratado com fidelidade o que estava sendo medido.

Apesar de o modelo de expectativa/não-confirmação ter sido testado em somente uma amostra de uma organização de serviços e, portanto, não ser representativo para todas as áreas de serviço ou mesmo para outras áreas de serviço médico, representa um tipo de serviço onde há uma interação intensa entre o profissional e o cliente. Como medida de validade, a pesquisa obteve valores de 0,60 para o coeficiente de determinação. No final, pode- se considerar apropriado para avaliar a qualidade dos serviços com estas características, mesmo a hipótese do Gap 2 tendo sido rejeitada.

\section{Modelo de avaliação de serviço e valor}

Bolton; Drew (1991) propuseram um método de avaliação envolvendo o valor a ser pago pelo serviço como parte do comportamento do cliente. A Figura 5 acrescenta elementos adicionais nas pesquisas sobre satisfação de clientes, representadas pelos conectores com fundo branco. Os elementos com fundo cinza representam o modelo SERVQUAL anteriormente citado.

Os autores sugerem um modelo mais elaborado segundo o qual as expectativas, desempenho percebido e a nãoconfirmação das expectativas são antecedentes da satisfação do cliente, sendo esta satisfação um dos fatores que afetam a percepção da qualidade do serviço. Um outro fator influente na percepção da qualidade do serviço é a própria não-confirmação das expectativas.

Figura 5: Avaliação da Qualidade de Serviço e Valor (BOLTON e DREW, 1991).

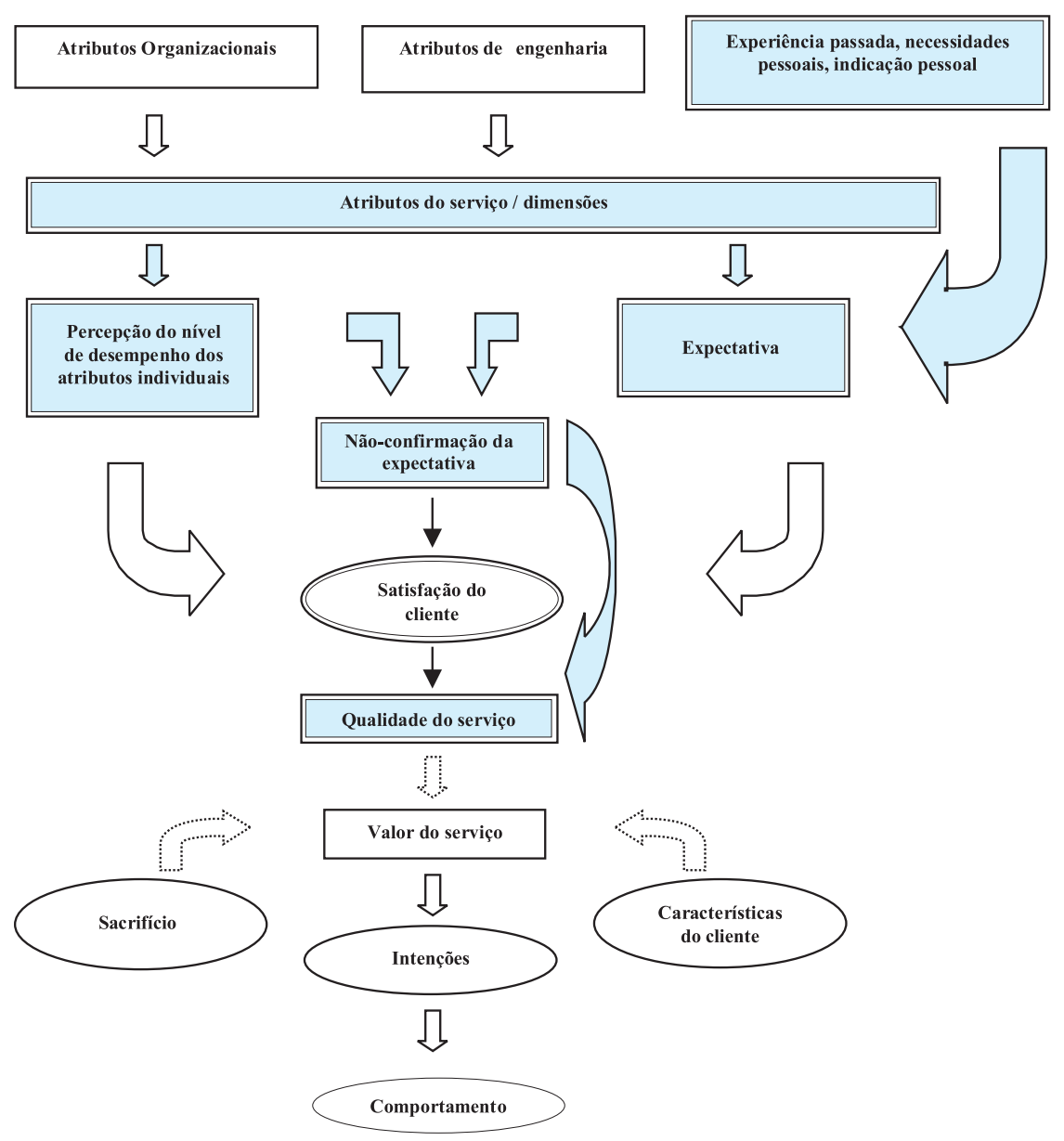


A avaliação de valor do serviço é uma função da qualidade do próprio serviço e dos sacrifícios envolvidos na sua aquisição, além das características dos clientes. Sacrifício é uma variável que descreve custos monetários e não-monetários associados à utilização dos serviços. A influência destas variáveis na avaliação de valor do serviço é representada pelos conectores pontilhados na $\mathrm{Fi}$ gura 5. Somente após a formação do conceito pessoal de valor do serviço é que serão delineados as intenções e o comportamento do cliente em relação ao consumo de um serviço. A partir do modelo da Figura 5, assumiram-se as seguintes relações:

$$
\begin{aligned}
& \mathrm{D}=\mathrm{f}_{1}(\mathrm{~S}) \\
& \mathrm{Q}=\mathrm{f}_{2}(\mathrm{D}, \mathrm{E},(\mathrm{D}-\mathrm{E})) \\
& \mathrm{V}=\mathrm{f}_{3}(\mathrm{Q}, \mathrm{Sc}, \mathrm{Cr}) \\
& \mathrm{V}=\mathrm{f}_{4}[\mathrm{Q}, \mathrm{Sc}, \mathrm{Cr}, \mathrm{D}, \mathrm{E},(\mathrm{D}-\mathrm{E})]
\end{aligned}
$$

\section{Onde:}

$\mathrm{D}=$ Valores de percepção de desempenho do serviço $\mathrm{k}$

$\mathrm{Q}=$ Valores de percepção de qualidade do serviço

$\mathrm{E}=$ Valores para expectativa do cliente em relação ao serviço

$\mathrm{V}=$ Medida de valor do serviço

$\mathrm{Sc}=$ Valor para o sacrifício envolvido na aquisição do serviço

$\mathrm{Cr}=$ Característica do cliente

Na avaliação de desempenho, $D$ corresponde a valores perceptíveis para atributos que descrevem o serviço $k$, e $f_{1}$ é uma função com parâmetros que dependem da natureza deste serviço. A avaliação da qualidade dos serviços tem como variáveis o desempenho avaliado no momento da aquisição do serviço, a expectativa do cliente e a não confirmação destas expectativas.

Como na literatura existe a hipótese de que os componentes da qualidade do serviço são avaliados de forma diferente quando se avalia concomitantemente seu valor, esta hipótese é testada através das equações (6) e (7), que têm funções diferentes, $\mathrm{f}_{3}$ e $\mathrm{f}_{4}$.

A aplicação do modelo ocorreu em três etapas distintas, avaliando-se as percepções de desempenho, a qualidade do serviço e, posteriormente, o valor a ele associado, para serviços telefônicos residenciais de ligações em todo o território norte-americano. A pesquisa envolveu 1.408 respondentes avaliando características previamente identificadas do instrumento SERVQUAL, considerando as cinco dimensões apontadas anteriormente, exceto os aspectos tangíveis que não foram considerados, pois o contato com a companhia é feito de forma automatizada, não havendo necessidade de demonstração dos equipamentos, instalações e pessoal envolvido para o consumo e avaliação do serviço.

Um ponto importante nessa pesquisa, foi a adaptação dos questionários para a área de telecomunicações, e que as medições avaliaram primeiramente a satisfação do cliente, de acordo com as equações anteriores, e não conforme o instrumento SERVQUAL. As características foram medidas em uma escala Lickert de 4 pontos (fraco, regular, bom e excelente).

$\mathrm{Na}$ discussão dos resultados, os pesquisadores observam que a não-confirmação das expectativas dos clientes explica uma maior proporção da variabilidade da qualidade dos serviços que o próprio desempenho, enquanto que, em estudos prévios, o desempenho explicava a maior proporção da variabilidade da satisfação de clientes, em relação à não-confirmação das expectativas. Os autores concluíram também que a não-confirmação das expectativas era mais importante na avaliação do valor dos serviços que na avaliação da qualidade dos serviços. Finalmente, as características dos clientes eram mais importantes para a avaliação do valor que para a avaliação da qualidade do serviço. Esta última conclusão traz implicações no gerenciamento de uma empresa de serviços, considerando que o valor percebido de um serviço é uma medida mais geral e significativa que a própria qualidade do serviço.

Os autores sugerem, com base nos resultados da pesquisa, que os provedores de serviço devem oferecer serviços mais flexíveis que possam satisfazer as diferentes preferências e expectativas de cada segmento de mercado. Afirmam que há necessidade de maior pesquisa para explorar os antecedentes da satisfação dos clientes, qualidade dos serviços e valor dos serviços, além de levantar questões sobre as medidas e escalas adotadas que melhor se adaptem para este tipo de pesquisa.

\section{Modelo SERVPERF}

Cronin e Taylor (1992) desenvolveram um modelo baseado somente na percepção de desempenho de serviços. Os autores ressaltam ainda que a qualidade é conceituada mais como uma atitude do cliente nas dimensões da qualidade, e que não deve ser medida com base no modelo de satisfação de Oliver (1980), ou seja, através das diferenças entre expectativa e desempenho, mas somente pelo desempenho, expresso por:

$\mathrm{Q}_{\mathrm{i}}=\mathrm{D}_{\mathrm{i}}$
Sendo:
$\mathrm{Q}_{\mathrm{i}}=$ Avaliação da qualidade do serviço em relação à


característica $i$.

$\mathrm{D}_{\mathrm{i}}=$ Valores de percepção de desempenho para a característica i de serviço.

Os autores denominaram de escala SERVPERF, como uma alternativa ao instrumento SERVQUAL, considerando ainda que os 22 itens representando as cinco dimensões da qualidade em serviço, propostos por Parasuraman et al. (1988) estavam bem embasados teoricamente. Assim, os 22 itens foram utilizados para avaliação de desempenho, testando quatro hipóteses:

1. Uma medida de qualidade em serviço SERVPERF não ponderada é mais apropriada para a medição da qualidade em serviço que o instrumento SERVQUAL, SERVQUAL ponderado, ou SERVPERF ponderado.

2. Satisfação do cliente é um antecedente da qualidade perceptível de serviço.

3. Satisfação do cliente tem um impacto significativo nas intenções de recompra.
4. Qualidade perceptível de serviço tem um impacto significativo nas intenções de recompra.

No trabalho foram aplicadas quatro séries de questões em empresas representantes dos seguintes setores: bancos, controle de pragas, lavanderia e lanchonete. Usando os mesmos itens aplicados no instrumento SERVQUAL, os questionários (com escala Lickert de 7 pontos) incluíam ainda uma avaliação para cada um dos itens quanto a sua importância, visando obter uma ponderação (mostrada na Tabela 4), e um questionário adicional (Figura 6). O questionário adicional compreendia três questões com o objetivo de avaliar os sentimentos a respeito da empresa fornecedora de serviços, a satisfação do cliente, a qualidade total dos serviços e a intenção de recompra.

Cronin; Taylor (1992) concluem que o instrumento SERVPERF é mais sensível em retratar as variações de qualidade em relação às outras escalas testadas. Esta conclusão foi baseada na utilização do teste estatístico do

Tabela 4: Questionário de Importância dos Itens (CRONIN e TAYLOR, 1992).

\begin{tabular}{|c|c|}
\hline ITEM & IMPORTÂNCIA \\
\hline 1 & Equipamentos modernos. \\
\hline 2 & Instalações físicas são visualmente atrativas. \\
\hline 3 & Os empregados são bem-vestidos e asseados. \\
\hline 4 & A aparência das instalações físicas é conservada de acordo com o serviço oferecido. \\
\hline 5 & Quando algo é prometido em um certo tempo é cumprido. \\
\hline 6 & Quando há algum problema com a empresa, ela é solidária e o deixa seguro. \\
\hline 7 & Tem confiabilidade. \\
\hline 8 & Fornece o serviço no tempo prometido. \\
\hline 9 & Mantém seus registros de forma correta. \\
\hline 10 & Informa exatamente quando os serviços serão executados. \\
\hline 11 & Recebe serviço imediato. \\
\hline 12 & Empregados estão sempre dispostos a ajudar os clientes. \\
\hline 13 & Empregados não estão sempre ocupados para responder aos pedidos dos clientes. \\
\hline 14 & Empregados são confiáveis. \\
\hline 15 & O sentimento de se sentir seguro em negociar com os empregados da empresa. \\
\hline 16 & Empregados são educados. \\
\hline 17 & Suporte adequado da empresa para cumprir suas tarefas corretamente. \\
\hline 18 & Atenção individual. \\
\hline 19 & Empregados dão a você atenção pessoal. \\
\hline 20 & Empregados sabem das suas necessidades. \\
\hline 21 & Os objetivos da empresa são os seus objetivos. \\
\hline 22 & Horário de trabalho conveniente. \\
\hline
\end{tabular}


qui-quadrado como prova de aderência das distribuições empíricas de dados e também o coeficiente da regressão linear dos dados.

Com referência à relação causal da qualidade em serviço, os pesquisadores afirmam que a literatura sugere que satisfação de cliente é um antecedente à qualidade de serviços, citando como exemplo o trabalho de Bolton e Drew (1991). Entretanto, Cronin e Taylor (1992) concluíram que a qualidade de serviço leva à satisfação do cliente. Esta relação de causalidade entre qualidade de serviços e satisfação foi determinada através da técnica de modelamento de equações estruturais com variáveis latentes (sendo mais comum ser chamada de "software LISREL”, conforme ALLEN e RAO, 2000).

Com relação à terceira e quarta questões da pesquisa, a satisfação do cliente levaria à intenção de compra para as quatro amostras dos quatro setores analisados, enquanto que qualidade de serviço seria a causa da intenção de compra para somente dois setores dos quatro analisados.

Os autores fazem também outras importantes considerações. Como a qualidade dos serviços é antecedente à satisfação do cliente, e como a satisfação do cliente tem uma forte relação na intenção de recompra, ações administrativas deveriam considerar programas de satisfação de clientes baseados em estratégias de qualidade de serviços. Salientam ainda que o maior problema na literatura é a hesitação em identificar claramente a qualidade perceptível dos serviços como uma atitude de recompra e a condução das pesquisas sobre qualidade de serviço não ser consistente com a literatura sobre satisfação e atitude.

Afirmam ainda que, segundo o trabalho pioneiro de Oliver (1980), a intenção de recompra é função da atitude. A atitude é função da expectativa inicial, e nas aquisições subseqüentes a atitude é uma função da atitude prévia e também do nível atual de satisfação com o serviço. Resumindo, tem-se a seguinte seqüência:
- Na ausência de experiência prévia com um fornecedor, somente a expectativa inicial define o nível de qualidade perceptível;

- Experiências subseqüientes com o fornecedor conduzem a novas não-confirmações de expectativas, modificando o nível de qualidade perceptível do serviço;

- O nível de qualidade perceptível do serviço redefinido modifica a intenção de recompra de um cliente.

Considerando as afirmações anteriores, Cronin e Taylor (1992) questionam a validade do instrumento SERVQUAL, criado a partir da não-confirmação da expectativa como a medida primária da qualidade perceptível de serviço, e consideram que a proposta da medida de desempenho SERVPERF está mais alinhada com os conceitos teóricos. Os autores concluem com uma crítica afirmando que:

- "qualidade perceptível de serviços é mais bem conceituada como uma atitude";

- "o modelo proposto é mais eficaz na operacionalização da qualidade dos serviços";

- "a medida de desempenho captura mais adequadamente a percepção da qualidade dos serviços pelo cliente".

Em um trabalho posterior, Parasuraman et al. (1994) respondem às críticas feitas por Cronin; Taylor (1992) e propõem uma agenda para pesquisa. Quanto às críticas teóricas, afirmam que o questionário SERVQUAL é um instrumento para medição da qualidade percebida dos serviços, no nível de atitude, em um determinado ponto do tempo e independentemente do processo pelo qual o conceito global de qualidade é formado.

Com relação às distinções entre a satisfação de clientes e a qualidade de serviço, Parasuraman et al. (1994) ressaltam que a satisfação é uma avaliação específica, enquanto a qualidade de serviço é uma avaliação global

\section{Figura 6: Questões adicionais (CRONIN e TAYLOR, 1992).}

"O seguinte conjunto de afirmativas se refere aos sentimentos a XYZ. Favor responder circulando o número que reflete melhor a sua percepção."

1. No próximo ano meu uso de $X Y Z$ será:
Absolutamente nenhum
(1) (2) (3)
(4) (5)
(6) (7) Muito Freqüente
2. A qualidade de serviço de XYZ é:
Muito ruim
(1) (2)
(3)
(4) (5)
(6) (7) Excelente

3. Meus sentimentos em relação aos serviços de XYZ podem ser mais bem descritos como:
Muito insatisfeito
(1)
(2)
(3)
(4)
(5)
(6)
(7) Bastante satisfeito 
composta por várias avaliações específicas, com uma direção de causalidade no sentido de que a satisfação do cliente leva à qualidade em serviço. No entanto, propõem novas pesquisas, sugerindo que a direção de causalidade pode ser da qualidade do serviço para a satisfação de clientes. Os autores também afirmam que, quanto à avaliação da expectativa, ainda não há consenso entre o que deve ser medido: se o desejo em relação a uma característica, ou um padrão esperado pelo cliente para uma determinada característica.

Finalizando, Parasuraman et al. (1994) salientam que a medição de expectativas individuais para cada item é uma informação mais rica que somente a medição de desempenho, pois seriam detectadas áreas de deficiência quanto à satisfação dos clientes, com ações gerenciais diretas para cada dimensão considerada.

Em um trabalho subseqüente, Cronin; Taylor (1994) rebatem as críticas de Parasuraman et al. (1994). Entretanto, concordam quanto à necessidade de uma agenda de pesquisa dos modelos para esclarecer pontos de relação entre a qualidade dos serviços e a satisfação dos clientes, acrescentando o valor do serviço. Enfatizam também a dúvida conceptual de que o modelo original de Oliver (1980) foi desenvolvido para avaliar satisfação de clientes, baseada na sua expectativa e não-confirmação, e que foi estendido para avaliar a qualidade perceptível dos serviços.

\section{Modelo de desempenho ideal}

Teas (1993) também criticou conceitualmente o instrumento SERVQUAL porque Parasuraman et al. (1991) afirmaram que a percepção de qualidade pode ser interpretada como uma atitude, de acordo com modelos clássicos de atitude do ponto ideal. Para deixar mais clara esta crítica, o máximo valor numérico obtido para a qualidade de serviço, aplicando-se o instrumento SERVQUAL e julgando-se um determinado atributo, ocorreria quando a expectativa fosse equivalente $\mathrm{a}+1$ e o desempenho equivalente $a+7$, resultando em uma qualidade de serviço com valor +6 (7-1). Analogamente, o mínimo valor numérico obtido para a qualidade de serviço ocorreria quando a expectativa fosse equivalente $\mathrm{a}+7$ e o desempenho equivalente a +1 , resultando em uma qualidade de serviço com valor -6 (1-7). Assim, este método de medição refletiria os aumentos dos níveis de qualidade com incrementos de valores na faixa de -6 a +6 , havendo uma correspondência linear.

Segundo o modelo clássico de atitude do ponto ideal, Ginter apud Teas (1993) relata que se a percepção de desempenho supera o ponto ideal (expectativa ideal) deveria refletir em uma diminuição da qualidade percebida, perdendo a correspondência linear. Entretanto, o modelo SERVQUAL aponta para um aumento da qualidade percebida. Desta forma, a escala SERVQUAL não pode ser interpretada de acordo com os modelos clássicos de atitude do ponto ideal (TEAS, 1993).

Em resposta a esta crítica, Parasuraman et al. (1994) afirmaram que a linearidade ocorre porque os atributos considerados no questionário SERVQUAL são vetoriais, ou seja, tanto o desempenho ideal quanto a expectativa ideal assumiriam valores máximos da escala Lickert. Como exemplo, cita o tempo de atendimento em uma loja de varejo, cujo máximo desempenho e a máxima expectativa associados ao atributo tempo seria o menor valor (de tempo) possível. Quando os atributos não são vetoriais, existe um ponto ideal, cujo desempenho, além da expectativa, não reflete maiores níveis da qualidade percebida, citando como exemplo a amabilidade de um vendedor em uma loja. Parasuraman et al. (1994) ainda afirmam que todos os 22 itens têm características de atributos vetoriais, havendo uma continuidade entre as medidas de desempenho e qualidade em serviço, refutando a crítica.

Em seu trabalho empírico, Teas (1993) testa quatro modelos, classificando-os como ponderados e não-ponderados, pela importância de cada atributo, empregando os mesmos itens do instrumento SERVQUAL para as dimensões da qualidade. Os modelos testados foram:

- Modelo SERVQUAL (D-E), de acordo com equação 1.

- Modelo SERVQUAL (D-E) revisado, utilizando questionário revisado para expectativas, de acordo com equação 1.

- Modelo de desempenho ideal (DI), de acordo com:

$$
\mathrm{Q}=-1\left[\sum_{i=1}^{m} w_{i}\left|D_{i}-I_{i}\right|\right]
$$

Sendo:

$\mathrm{Q}$ = qualidade percebida do serviço

$\mathrm{D}_{\mathrm{j}}=$ valor de desempenho atribuído à característica $\mathrm{i}$ do serviço

$\mathrm{W}_{\mathrm{i}}$ = importância ou ponderação da característica i

$\mathrm{m}=$ número total de características

$\mathrm{I}_{\mathrm{i}}=$ valor ideal para a característica i atribuído ao serviço

- Modelo de qualidade normalizada do serviço (QN) usando as expectativas revisadas, de acordo com:

$$
\mathrm{QN}=\left[\sum_{i=1}^{m} w_{i}\left(\left|D_{i}-I_{i}\right|-\left|D_{e i}-I_{i}\right|\right)\right]
$$

Sendo:

$\mathrm{D}_{\mathrm{ei}}=$ valor de desempenho atribuído à característica j possuído por um serviço julgado como padrão de excelência 
$\mathrm{w}_{\mathrm{i}}=$ importância ou ponderação da característica $\mathrm{j}$

$\mathrm{I}_{\mathrm{i}}=$ valor do desempenho ideal para o característica $\mathrm{i}$

$\mathrm{D}_{\mathrm{i}}=$ valor de desempenho atribuído à característica $\mathrm{i}$

$\mathrm{m}=$ número de características

O trabalho empírico envolveu 120 respondentes aleatoriamente escolhidos pela lista telefônica, sendo questionados pessoalmente a respeito de três lojas de varejo, em 10 atributos dos 22 itens originais, sendo dois para cada uma das cinco dimensões; duas hipóteses foram testadas:

- $\mathrm{H}_{1}$ : a avaliação da qualidade através do modelo do desempenho ideal (DI) é melhor em relação aos modelos SERVQUAL, SERVQUAL revisado e qualidade normalizada (QN).

- $\mathrm{H}_{2}$ : a validação dos modelos envolvendo preferências de compra, intenções de recompra e satisfação total dos serviços é mais bem representada para o modelo de desempenho ideal (DI) em relação aos modelos SERVQUAL, SERVQUAL revisado e qualidade normalizada $(\mathrm{QN})$.

O resultado da aplicação dos testes indica que a hipótese $\mathrm{H}_{1}$ pode ser parcialmente rejeitada. $\mathrm{O}$ modelo do desempenho ideal (DI) não-ponderado apresentou maior correlação que os outros modelos não-ponderados. No entanto, o modelo do desempenho ideal (DI) ponderado apresentou menor correlação que o modelo SERVQUAL não ponderado. Assim, a segunda hipótese não pode ser estatisticamente refutada.

Resumindo, a pesquisa de Teas (1993), apesar de usar um limitado conjunto dos itens da escala SERVQUAL e não abranger todos os setores de serviços, aponta para o modelo do desempenho ideal (DI) como o mais representativo da satisfação do cliente, intenção de recompra e preferências de compra.

Contestando estes resultados, Parasuraman et al. (1994) observaram que se os atributos de serviço incluídos no estudo são tipicamente vetoriais e as conclusões encontradas dão margem a questionamento. Os autores propõem ainda um novo modelo que assumiria algumas características de atributos vetoriais e outras típicas de atributos do ponto ideal, sendo conceitualmente mais apropriados. Fazem restrições para esta última proposta quanto a operacionalização dos questionários, pois os respondentes deveriam explicitar o critério próprio de julgamento da expectativa para um determinado atributo, se vetorial ou ideal, alongando demasiadamente os questionários e, portanto, afetando a confiabilidade da aplicação do questionário.

Mais recentemente, Lee et al. (2000) fizeram uma pesquisa sobre qualidade em serviço, com o objetivo de examinar a influência de duas dimensões da qualidade de serviço: aspectos tangíveis e presteza, em relação ao tipo de serviço. Foram aplicadas 15 das 22 questões do instrumento SERVQUAL e SERVPERF, sendo três itens para cada dimensão, em um parque de entretenimento, uma academia de ginástica e em uma consultoria em investimentos. Os números dos respondentes foram 196, 197 e 128 , respectivamente, para cada empresa, usando a escala Lickert de 7 pontos.

Para a avaliação da qualidade, três hipóteses foram assumidas:

- $\mathrm{H}_{1}$ - o desempenho (SERVPERF) tem uma maior correlação com a qualidade de serviço quando comparado com a diferença entre desempenho e expectativa (SERVQUAL).

- $\mathrm{H}_{2}$ - a qualidade percebida de serviço é um antecedente da satisfação do cliente.

- $\mathrm{H}_{3}$ - aspectos tangíveis são mais importantes para as empresas de serviço com equipamentos e instalações do que para empresas cuja ênfase é o atendimento pessoal.

Como medida de confiabilidade dos instrumentos, utilizou o coeficiente alfa de Cronbach, que variou na faixa de 0,62 a 0,85 para todas as empresas pesquisadas.

Foi utilizada a análise de regressão múltipla com ambas as medidas, para cada uma das empresas, obtendose valores maiores do coeficiente de determinação ajustado $\left(\mathrm{R}^{2}\right)$ para o desempenho (SERVPERF), da ordem de 0,51 a 0,65 , não refutando a hipótese $\mathrm{H}_{1}$.

\section{S diferentes desenvolvimentos apresentam modelos que variam em termos de representação algébrica, características principais e conclusões acerca de sua aplicação.}

Testando a segunda hipótese $\left(\mathrm{H}_{2}\right)$, não foram obtidos resultados consistentes para todos os tipos de empresa, não podendo rejeitá-la. A terceira hipótese não foi rejeitada com a análise dos resultados da regressão.

Apesar das conclusões desta pesquisa não serem amplas o suficiente para uma generalização, demonstram a existência de restrições aos modelos existentes. Também confirmam uma maior adequação do instrumento SERVPERF em relação ao SERVQUAL.

Considerando o tipo de serviço altamente dependente do contato entre o atendente e o cliente, o gerenciamento 
deve ser direcionado para a dimensão presteza no atendimento, enquanto que empresas dependentes de instalações e equipamentos devem ter como prioridade gerencial a dimensão aspectos tangíveis, independentemente das pesquisas sobre satisfação e qualidade dos serviços.

A direção de causalidade entre satisfação do cliente, qualidade em serviço e intenção de compra ainda é objeto de pesquisa, não sendo totalmente esclarecida, em função de muitas controvérsias e resultados divergentes, até pela própria complexidade da área comportamental.

\section{SÍNTESE COMPARATIVA ENTRE OS MODELOS}

A Tabela 5 apresenta um quadro-resumo dos modelos de qualidade de serviço, visando fornecer uma referência para a pesquisa nesta área. A tabela mostra os autores, modelos e principais características de cada modelo, bem como inclui, na coluna da direita, a área de aplicação da pesquisa, que pode ser usada como um indicador da generalização do modelo de serviço ou se foi aplicado a um serviço específico. São também apresentadas as principais conclusões desses trabalhos. Essa coluna deve ser lida com reservas, pois é somente uma síntese das fontes pesquisadas, sendo mais conveniente reportar-se aos textos originais, para um maior detalhamento. balho de Lee et al. (2000) destaca que os aspectos tangíveis são mais importantes para empresas com instalações (como no caso de academias de ginástica).

Ainda que não tenha sido objetivo desse trabalho, foram identificados trabalhos que envolvem a avaliação da qualidade de serviços oferecidos para clientes internos (HESKETT et al., 1994; REYNOSO; MOORES, 1995; LOVEMAN, 1998; AUTY; LONG, 1999; KUEI 1999; GILBERT, 2000), com base nos modelos apresentados anteriormente. Na verdade, a busca pela satisfação de clientes externos tem contribuído para que uma maior atenção seja direcionada aos clientes internos. A importância da medição da qualidade dos serviços internos de uma empresa baseia-se em pesquisas recentes motivadas pela evolução de um ambiente empresarial de livre mercado e altamente competitivo, notadamente nos Estados Unidos (VAVRA, 1997).

\section{CONSIDERAC̣ÕES FINAIS E PERSPECTIVAS PARA TRABALHOS FUTUROS}

Primeiramente faz-se necessário mencionar que a revisão da literatura levanta algumas questões em relação à medição da qualidade em serviços externos, que não foram resolvidas por completo pelos pesquisadores, sugerindo uma falta de consenso. Cita-se como exemplo a relação de causalidade entre qualidade dos serviços e satisfação de clientes, e a influência do preço na satisfação do cliente, o que pode ser identificado como uma primeira perspectiva para estudos futuros. Também pode ser citada a seleção de um dos modelos de qualidade em serviços, que seja mais apropriado a dada aplicação. Nesse sentido, uma aplicação dos quatro principais modelos (SERVQUAL, SERVPERF, ambos na sua forma ponderada e não ponderada) pode ser considerada como uma segunda possibilidade

Embora os trabalhos apresentados demonstrem que cada um dos modelos é teoricamente bem embasado e adequado para as aplicações propostas, pode-se afirmar que não existe ainda um consenso na literatura sobre qual modelo é mais apropriado. Alguns trabalhos empíricos, como o de Lee et al. (2000), apontam que o modelo SERVPERF retrata melhor a qualidade de serviços que o modelo SERVQUAL. No entanto, entende-se que ainda não é possível ser conclusivo sob esse aspecto. Outro tema que merece destaque é relacionado à relação causal entre as dimensões da qualidade e o tipo de empresa prestadora de serviços. Nesse sentido, novamente o tra- para trabalhos futuros.

Outro aspecto é quanto à generalização das dimensões para todos os tipos de serviços. Ainda há controvérsias quanto a generalização das cinco dimensões da qualidade e a influência de cada uma destas dimensões na percepção de qualidade, considerando tipos diversos de serviços. Sendo assim, uma terceira alternativa para pesquisas futuras é testar os modelos em tipos distintos de serviços.

Estas três importantes perspectivas para estudos sobre a qualidade dos serviços devem direcionar a pesquisa focando no setor de serviços em relação a clientes externos. No entanto, paralelamente às necessidades por pes- 
quisa na área de qualidade de serviços e satisfação de clientes externos também existe uma demanda pela pesquisa em serviços internos, embora não tenha sido foco específico desse trabalho. Nesse sentido, pode-se citar o trabalho de Kang et al. (2002) e outros que sugerem a utilização dos modelos de avaliação da qualidade em serviços com clientes externos para clientes internos. A pesquisa direcionada aos clientes internos poderá utilizar-se das soluções encontradas para as empresas de serviços externos com as devidas adaptações. Assim, pode-se sugerir um quarto tema para trabalho futuro a partir desta revisão da literatura.

Tabela 5: Resumo dos Modelos de Qualidade da Literatura.

\begin{tabular}{|c|c|c|c|c|}
\hline AUTOR & MODELO & $\begin{array}{l}\text { CARACTERÍSTICAS } \\
\text { PRINCIPAIS }\end{array}$ & $\begin{array}{l}\text { CONCLUSÕES } \\
\text { PRINCIPAIS }\end{array}$ & $\begin{array}{l}\text { ÁREA DE } \\
\text { APLICAÇÃ̃O }\end{array}$ \\
\hline Grönroos (1984) & $\begin{array}{l}\text { Não apresenta } \\
\text { modelo com } \\
\text { representação } \\
\text { algébrica }\end{array}$ & $\begin{array}{l}\text { Qualidade = } \\
\text { f(expectativa, } \\
\text { desempenho e } \\
\text { imagem) }\end{array}$ & $\begin{array}{l}\text { - Interação comprador / } \\
\text { vendedor é mais importante } \\
\text { que atividades de marketing. } \\
\text { - Contato comprador/ } \\
\text { vendedor tem mais influência } \\
\text { na formação da imagem que } \\
\text { atividades de marketing. }\end{array}$ & $\begin{array}{l}\text { Diversos tipos de } \\
\text { serviços }\end{array}$ \\
\hline $\begin{array}{l}\text { Parasuraman et al. } \\
\text { (1985,1988) }\end{array}$ & $\begin{array}{l}\text { SERVQUAL } \\
Q_{i}=D_{i}-E_{i}\end{array}$ & $\begin{array}{l}22 \text { itens distribuídos } \\
\text { em cinco dimensões } \\
\text { da qualidade }\end{array}$ & $\begin{array}{l}\text { - A qualidade de serviços pode } \\
\text { ser quantificada. } \\
\text { - Determina cinco dimensões } \\
\text { genéricas para todos os tipos } \\
\text { de serviços. } \\
\text { - A qualidade dos serviços é } \\
\text { diferença entre expectativa e } \\
\text { desempenho ao longo das } \\
\text { dimensões. }\end{array}$ & $\begin{array}{l}\text { Diversos tipos de } \\
\text { serviços }\end{array}$ \\
\hline $\begin{array}{l}\text { Brown e Swartz } \\
\text { (1989) }\end{array}$ & $Q_{i}=E_{i}-D_{i}$ & $\begin{array}{l}\text { Utiliza as } 10 \\
\text { dimensões } \\
\text { desenvolvidas por } \\
\text { Parasuraman et al. } \\
\text { (1985) }\end{array}$ & $\begin{array}{l}\text { - A qualidade dos serviços é a } \\
\text { diferença entre desempenho e } \\
\text { expectativa ao longo das } \\
\text { dimensões. }\end{array}$ & $\begin{array}{l}\text { Atendimento em } \\
\text { consultórios da } \\
\text { área médica }\end{array}$ \\
\hline $\begin{array}{l}\text { Bolton e Drew } \\
\text { (1991) }\end{array}$ & $\begin{array}{l}\text { Modelo de } \\
\text { Avaliação do } \\
\text { serviço e valor } \\
\text { Representado por } \\
\text { várias equações } \\
\text { algébricas }\end{array}$ & $\begin{array}{l}\text { - Utiliza quatro } \\
\text { dimensões } \\
\text { desenvolvidas por } \\
\text { Parasuraman et al. } \\
\text { (1988) } \\
\text { - Introduz o conceito } \\
\text { do valor na avaliação } \\
\text { da qualidade do } \\
\text { cliente }\end{array}$ & $\begin{array}{l}\text { - Concluem que as } \\
\text { características dos clientes } \\
\text { influenciam as avaliações de } \\
\text { qualidade e valor pelo } \\
\text { cliente. } \\
\text { - A não confirmação das } \\
\text { expectativas está mais } \\
\text { fortemente correlacionada } \\
\text { com a qualidade dos serviços. }\end{array}$ & $\begin{array}{l}\text { Serviços de } \\
\text { telefonia }\end{array}$ \\
\hline $\begin{array}{l}\text { Cronin e Taylor } \\
\text { (1992) }\end{array}$ & $\begin{array}{l}\text { SERVPERF } \\
Q_{i}=D_{i}\end{array}$ & $\begin{array}{l}\text { Utiliza as cinco } \\
\text { dimensões gerais } \\
\text { desenvolvidas por } \\
\text { Parasuraman et al. } \\
\text { (1988) }\end{array}$ & $\begin{array}{l}\text { - Avaliação de qualidade de } \\
\text { serviços é melhor } \\
\text { representada pela } \\
\text { desempenho ao longo das } \\
\text { dimensões }\end{array}$ & $\begin{array}{l}\text { Diversos tipos de } \\
\text { serviços }\end{array}$ \\
\hline Teas (1993) & $\begin{array}{l}\text { Modelo do } \\
\text { Desempenho Ideal } \\
\mathrm{Q}_{\mathrm{i}}=-\left[\sum_{i=1}^{m} w_{i}\left|\mathrm{D}_{\mathrm{i}}-\mathrm{I}_{\mathrm{i}}\right|\right]\end{array}$ & $\begin{array}{l}\text { Utiliza as cinco } \\
\text { dimensões gerais } \\
\text { desenvolvidas por } \\
\text { Parasuraman et al. } \\
\text { [1988] }\end{array}$ & $\begin{array}{l}\text { - O modelo do desempenho } \\
\text { ideal tem maior correlação } \\
\text { com as preferências de } \\
\text { compra, intenções de } \\
\text { recompra e satisfação com } \\
\text { os serviços }\end{array}$ & Lojas de varejo \\
\hline
\end{tabular}


Mais especificamente, a continuidade desse trabalho envolve uma comparação entre os resultados da aplicação dos modelos de avaliação da qualidade em serviços apresentados neste artigo. Pretende-se, num primeiro momento, a utilização das escalas voltadas para avaliação da qualidade de serviços considerando clientes internos, visando estudar a viabilidade dessas escalas para esses tipos de serviços. Pode-se ainda realizar uma comparação entre os resultados na aplicação das escalas existentes, objetivando identificar se alguma delas é mais eficaz. Nesse sentido, pretende-se avaliar os serviços internos de manutenção em uma empresa de manufatura, utilizando-se das escalas existentes. Espera-se avaliar a aplicabilidade das escalas, sua confiabilidade, bem como identificar as dimensões da qualidade mais significativas para os usuários desses serviços. Esse trabalho será relatado futuramente.

\section{Artigo recebido em 26/03/2003 Aprovado para publicação em 23/01/2004}

\section{- Bibliografia}

ALLEN, D.; RAO, T. Analysis of Customer Satisfaction Data, ASQ Quality Press, Milwaukee, Wisconsin, 2000.

AUTY, S.; LONG, G., Tribal warfare and gaps affecting internal service quality. International Journal of Service Industry Management, v. 10, n. 1, p. 7-22, 1999.

BABAKUS, E.; BOLLER, G.W. An empirical assessment of the Servqual Scale. Journal of Business Research, v. 24, p. 253-68, 1992

BROWN, S.W.; SWARTZ, T. A. A gap analysis of professional service quality. Journal of Marketing, v. 53, n. 2, p. 92-8, 1989.

BOLTON, R. D.; DREW, J.H. A multistage model of customers' assessment of service quality and value. Journal of Consumer Research, v. 17 , n. 4, p. 375-84, 1991.

BUTKOVICH, N.J. Reshelving study of review literature in the physical science. Library Resources, v. 40, n. 2, p. 139-144, 1996.

CARMAN, J.M. Consumer perceptions of service quality: an assessment of the Servqual dimensions, Journal of Retailing, v. 66, n. 1, Spring, p. 33-55, 1990.

CRONIN, J.; TAYLOR, S. Measuring service quality: A reexamination and extension. Journal of Marketing, v. 56, n. 3 , p. 55-68, 1992.
CRONIN, J.; TAYLOR, S. Servperf versus Servqual: reconciling performance based and perceptions minus expectations measurement of service quality, Journal of Marketing, v. 58 , n. 1, p.125-31, 1994.

GIL, A.C. Como Elaborar Projetos de Pesquisa. São Paulo: Atlas, 1991.

GILBERT, G. R. Measuring internal customer satisfaction, Managing Service Quality, v. 10, n. 3, p. 178-86, 2000 .

GRÖNROOS, C. A service quality model and its marketing implications. European Journal of Marketing. v. 18, n. 4, p. 36-44, 1984.

HESKETT et al. Putting a service profit chain to work. Harvard Business Review, v. 72, n. 2, March-April, p. 164-74, 1994

IBGE. Instituto Brasileiro de Geografia e Estatística. Indicadores Conjunturais. Rio de Janeiro, 2002. Disponível em: <http:// w w w 2. i b g e.gov. b r / p u b / Trabalho_e_Rendimento/ Pesquisa Mensal de Emprego/ fasciculo indicadores ibge/ $>$. Acesso em: 22 nov. 2002

KANG, G. D., JAMES, J., ALEXANDRIS K. Measurement of internal service quality: application of the Servqual battery to internal service quality. Managing Service Quality, v. 12, n. 5, p. 278-91, 2002.

KUEI, C. H. Internal service quality an empirical assessment, International Journal of quality and Reliability Management, v. 16, n. 8, p. 783-91, 1999.
LEE H.; LEE Y.; YOO D., The determinants of perceived service quality and its relationship with satisfaction. Journal of services marketing, v. 14, n. 3, p. 217-31, 2000

LOVEMAN, G.W. Employee satisfaction, customer loyalty, and financial performance: an empirical examination of the service profit chain in retail banking, Journal of Service Research v. 1, p. 18-31, November, 1998.

NORONHA, D.P.; FERREIRA, S.M.S.P., Revisões da Literatura. In: CAMPELLO, B.S., CENDÓN, B.V. e KREMER, J.M. Fontes de Informação para Pesquisadores e Profissionais. Belo Horizonte: Editora UFMG, p. 191$198,2000$.

OLIVER, R.L. A Cognitive model of the antecedents and consequences of satisfaction decisions, Journal of Marketing Research, v. 17, n. 4 , November, p. 460-69, 1980.

PARASURAMAN, A.; ZEITHAML V.A BERRY, L.L. A conceptual model of services quality and its implication for future research. Journal of Marketing, v. 49, n. 4, p. 41-50, 1985

PARASURAMAN, A.; ZEITHAML V. A.; BERRY, L. L. Servqual: A multipleitem scale for measuring consume perceptions of service quality. Journal of Retailing, v. 64, n. 1, p. 1240, 1988.

PARASURAMAN, A.; ZEITHAML V. A BERRY, L.L., Delivering quality service. Balancing customer perceptions and expectations. New York: The Free Press, 1990
PARASURAMAN, A. ZEITHAML VA. BERRY, L.L. Refinement and reassessment of the Servqual Scale, Journal of Retailing, v. 67, n. 4, p. 420-50, 1991.

PARASURAMAN, A.; ZEITHAML V. A. BERRY, L.L., Reassessment of expectation as a comparison standard in measuring service quality: implications for further research, Journal of Marketing, v. 58 n. 1 , p. $111-24,1994$

REYNOSO, J.; MOORES, B. Towards the measurement of interna service quality. International Journal of Service, v. 6, n. 3, p. 6483, 1995.

SLACK, N. Is there a "third world" in the "two worlds" debate? Sessão Plenária na Euroma-POMS Conference, Itália, 2003. Disponível: <http://www e u rom a pom s 2003 . or g/ download presentations.aspx $>$. Acesso: 15 de dezembro de 2003.

SAYERS. M.; JOICE, J.; BAWDEN, D Retrieval of biomedical reviews: a comparative evaluation of online databases for reviews of drug therapy. Journal of Information Science, v. 16, p. 321-325, 1990.

TEAS, R.K. Expectations, performance evaluation and consumer's perceptions of quality. Journal of Marketing, v. 57, n. 4, October, p. 18-34, 1993

\section{- Agradecimentos}

Os autores do trabalho agradecem aos revisores pela análise crítica da primeira versão do artigo e pelas sugestões, as quais a maior parte delas foi implementada. Também agradecem ao Sr. Waldemar Peres Júnior pela revisão profissional do texto. 